\title{
Comparing User Rights in the Privacy Policies Presented by Major Websites in Korea, the United States, and the United Kingdom
}

\author{
Hansol Woo' ${ }^{1}$ and Jinho Yoo, ${ }^{2, *}$ \\ ${ }^{1,2}$ Department of Business Administration, Sangmyung University, Seoul, Republic of Korea.
}

ORCID: 0000-0003-4359-8009 (Jinho Yoo)

\begin{abstract}
In this paper, we compare the privacy policies presented by major websites in Korea, the United States, and the United Kingdom and find out what differences are there in terms of user rights. For this research, a total of 18 major shopping malls, telecommunication companies, portal sites, etc. were selected and analyzed. To compare user rights items in the privacy policies, the Personal Information Protection Act of Korea and the European GDPR were set as criteria and quantitative comparisons. Comparisons were conducted by the scores that were calculated differentially according to the specific and clearly presented degree.
\end{abstract}

Keywords: Privacy Policy, User Rights

\section{INTRODUCTION}

Service Providers who collect and use personal information shall handle it safely from collection to use, provision, management and destruction in accordance with the principle of personal information protection and related laws. In addition, the service provider's processing Privacy Policy on how the personal information provided to the data subject is managed and used should be established and disclosed so that data subject can know how his or her information is handled.

The Personal Information Protection Act stipulates that the right to withdraw consent for collection and use of personal information, the right to select and decide whether to agree to process, the right to receive information on processing, the right to request access to personal information of children under 14 years of age, the right to request suspension of processing, the right to request correction, the right to request for deletion and fair remedy, etc. should be guaranteed.

As stipulated in Article 30 of the PERSONAL INFORMATION PROTECTION ACT of Korea (establishment and disclosure of personal information processing policies), the personal information processor shall include matters concerning the provision of personal information to third parties, matters concerning the consignment of personal information processing, the rights, duties, and matters concerning the methods of exercise of data subject and legal representative.

Therefore, companies are making Privacy Policy and showing them on their websites so that people can see them anytime. In addition, the Privacy Policy specified at the bottom of each homepage is marked in bold colors so that it can be seen clearly by the user rather than other information.

In this paper, we compared the privacy policies of user rights presented by major websites in Korea, the United States, and the United Kingdom, and find out what characteristics and differences they represent, and compare them with legal criteria items to find implications.

\section{LITERATURE REVIEW}

Starting with Lee Min-young (2012), there are studies on personal information processing policies such as Jang Wonchang (2012), Noh Seung-hoon (2014), Jeon Chang-wook (2016). In 2012, Lee Min-young analyzed the legal issues of Google's personal information processing policy change through "whether to expand the scope of personal information use without explicit consent from users," "whether to obtain consent for personal information processing policies when signing up for membership," and "whether to omit essential Privacy Policy." Based on these points, the regulation on the withdrawal of consent and explicit recognition of the integrated management was applied, and the direction was suggested that the personal information collector could not use and provide the user's personal information for any purpose other than the intended purpose without explicit consent. [1]

Jang Won-chang etc. (2012) analyzed the impact on online transactions on how Internet users perceive and check their privacy policies. And he showed that the more experienced the personal information infringement, the more likely it is to check the privacy policy.

Noh Seung-hoon (2014) conducted a study on measuring the time required to read the privacy policy. The estimated time required to read the privacy policy for a month was measured from 8.83 minutes to 34.03 minutes. Through this, it was suggested that items that Internet users are interested in should be included at the top of the privacy policy, and that if other items are checked directly by the user using a separate hyperlink, the time required to read the privacy policy can be reduced and the self-control of personal information can be strengthened. [4]

Chang-wook Jeon (2016) conducted a study to analyze differences and characteristics by comparing privacy policies of domestic and foreign portals and sites by domestic industry. Through this, it revealed the differences and distances by industry, narrowed them, and suggested the need for efforts to minimize the disadvantages caused by the differences. [5]

\footnotetext{
*Corresponding Author. E-mail: jhyoo@smu.ac.kr
} 
International Journal of Engineering Research and Technology. ISSN 0974-3154, Volume 13, Number 9 (2020), pp. 2437-2443

(C) International Research Publication House. https://dx.doi.org/10.37624/IJERT/13.9.2020.2437-2443

\section{METHODOLOGY}

\subsection{Selection of research subjects}

We selected and analyzed a total of 18 sites, two sites for major shopping malls, telecommunications companies, and portal sites in Korea, the United States, and the United Kingdom.

Table 1. Selection major websites in Korea, the United States and the United Kingdom.

\begin{tabular}{|c|c|c|c|}
\hline & Shopping malls & Mobile carriers & Portal Sites \\
\hline Korea & Gmarket, & SKT, & Naver, \\
$(6$ companies $)$ & 11 st & KT & Daum \\
\hline US & Amazon, & Verizon, & Yahoo, \\
$(6$ companies $)$ & Ebay & AT\&T & Bing \\
\hline UK & ASOS, & Vodafone, & Excite UK \\
\hline
\end{tabular}

We used the privacy policies of each site disclosed from the period shown in Table 2 to the time of the investigation period.

Table 2. Date of implementation of the Privacy Policy based on the standard

\begin{tabular}{|c|c|c|c|}
\hline Country & \multicolumn{2}{|c|}{ Site } & Date of implementation \\
\hline \multirow{6}{*}{$\mathrm{KR}$} & \multirow{2}{*}{ Shopping Malls } & Gmarket & 2018.02.26. \\
\hline & & $11 \mathrm{st}$ & 2018.02.01. \\
\hline & \multirow{2}{*}{ Mobile carriers } & SKT & 2018.02.12. \\
\hline & & KT & 2018.02.08. \\
\hline & \multirow{2}{*}{ Portal Sites } & Naver & 2018.02.14. \\
\hline & & Daum & 2018.01.15. \\
\hline \multirow{6}{*}{ US } & \multirow{2}{*}{ Shopping Malls } & Amazon & 2017.08.29. . \\
\hline & & Ebay & $2018.02 \sim$ \\
\hline & \multirow{2}{*}{ Mobile carriers } & Verizon & $2018.01 \sim$ \\
\hline & & AT\&T & 2017.05.02. \\
\hline & \multirow{2}{*}{ Portal Sites } & Yahoo & 2017.06.13. \\
\hline & & Bing & 2018.02. \\
\hline \multirow{6}{*}{ UK } & \multirow{2}{*}{ Shopping Malls } & ASOS & 2018.01.03. \\
\hline & & NEW LOOK & $2018.01 \sim$ \\
\hline & \multirow{2}{*}{ Mobile carriers } & Vodafone & $2018.01 \sim$ \\
\hline & & BT Group & $2018.01 \sim$ \\
\hline & \multirow{2}{*}{ Portal Sites } & BBC Online & $2018.01 \sim$ \\
\hline & & Excite UK & $2018.01 \sim$ \\
\hline
\end{tabular}

\subsection{Selection of assessment items}

The terms of user rights specified in the GDPR include the right to oppose decision making, the right to receive information, access by data subjects, the right to request correction and revocation, the right to limit processing, the right to receive notification in correction, deletion and restriction, the right to move data, and the right to claim damages.

The contents of the user's rights stipulated in the PERSONAL INFORMATION PROTECTION ACT of Korea include the right to withdraw consent to collect, use, and transfer personal information, the right to select, decide, the right to receive and process information on personal information, the right to request access to personal information from legal representatives of children under the age of 14 , the right to request suspension of processing, and the right to cancel, right to cancel the information, right to delete and to request for correction.

The assessment items used in this analysis are classified as Table 3 based on the items specified in the PERSONAL INFORMATION PROTECTION ACT of Korea and those specified in the GDPR of Europe. To analyze the contents of the personal information processing policy of the sites, we 
International Journal of Engineering Research and Technology. ISSN 0974-3154, Volume 13, Number 9 (2020), pp. 2437-2443

(C) International Research Publication House. https://dx.doi.org/10.37624/IJERT/13.9.2020.2437-2443

scored it as 2 points if the items were specifically and clearly stated for each of the 9 criteria in Table 3, and 1 point if specified but not clear. And a non-specified score was scored as 0 to attempt quantitative comparison.

Table 3. User rights comparison assessment items presented in this paper

\begin{tabular}{|l|c|l|}
\hline \multicolumn{1}{|c|}{ Category } & No & \multicolumn{1}{|c|}{ Item } \\
\hline \multirow{2}{*}{ Choice } & 1 & Right to withdraw the consent of personal information collection, utilization, transferring, etc. \\
\cline { 2 - 4 } & 2 & Consent to treatment, consent, whether or not, select the range and right to decide \\
\hline \multirow{2}{*}{ Sharing } & 3 & Right to receive information on processing \\
\hline \multirow{2}{*}{ Reading } & 4 & Right to check processing status and request access to personal information \\
\cline { 2 - 4 } & 5 & $\begin{array}{l}\text { Right to request the child's personal information, including access to the child's personal } \\
\text { information by the legal representative of the child under the age of 14 }\end{array}$ \\
\hline \multirow{2}{*}{ Processing } & 6 & Right to require suspension of processing \\
\hline \multirow{2}{*}{ Correction and Delete } & 7 & Right to demand correction \\
\cline { 2 - 4 } & 8 & Right to require deletion and revocation \\
\hline Damage relief & 9 & Right to remedy damages caused by processing in a prompt and fair \\
\hline
\end{tabular}

\section{RESULT AND ANALYSIS}

\subsection{Comparison of shopping malls}

Results of Comparing and analyzing personal information processing policies on major shopping mall sites in Korea and abroad with comparison assessment items were that average score of Korean sites is 17 , that of U.S. sites is 3, and that of British sites is 10. In the case of major shopping mall sites in Korea, most of the contents of user rights that should be guaranteed by PERSONAL INFORMATION PROTECTION ACT of Korea are stated in the privacy policy.

Table 4. Shopping mall-based score

\begin{tabular}{|c|c|c|c|c|c|c|c|}
\hline \multirow{3}{*}{ 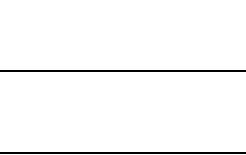 } & \multirow[b]{3}{*}{ No } & \multirow{2}{*}{\multicolumn{2}{|c|}{ KR }} & \multirow{2}{*}{\multicolumn{2}{|c|}{ US }} & \multicolumn{2}{|c|}{ (Total: 18} \\
\hline & & & & & & & \\
\hline & & Gmarket & $11 \mathrm{st}$ & Amazon & Ebay & ASOS & $\begin{array}{l}\text { NEW } \\
\text { LOOK }\end{array}$ \\
\hline \multirow{2}{*}{ Choice } & 1 & 2 & 2 & 0 & 2 & 2 & 0 \\
\hline & 2 & 2 & 2 & 2 & 2 & 2 & 2 \\
\hline Sharing & 3 & 2 & 2 & 0 & 0 & 0 & 2 \\
\hline \multirow{2}{*}{ Reading } & 4 & 2 & 2 & 0 & 0 & 2 & 2 \\
\hline & 5 & 2 & 2 & - & - & 0 & 0 \\
\hline Processing & 6 & 2 & 1 & 0 & 0 & 2 & 0 \\
\hline \multirow{2}{*}{$\begin{array}{c}\text { Correction and } \\
\text { Delete }\end{array}$} & 7 & 2 & 2 & 0 & 0 & 2 & 2 \\
\hline & 8 & 2 & 1 & 0 & 0 & 2 & 0 \\
\hline Damage relief & 9 & 2 & 2 & 0 & 0 & 0 & 0 \\
\hline \multicolumn{2}{|c|}{ Total } & 18 & 16 & 2 & 2 & 12 & 8 \\
\hline
\end{tabular}

※ Detailed and clearly specified.: 2 points

※ It is specified, but it is not clear.: 1 point

※ Not specified.: 0 point 
International Journal of Engineering Research and Technology. ISSN 0974-3154, Volume 13, Number 9 (2020), pp. 2437-2443

(C) International Research Publication House. https://dx.doi.org/10.37624/IJERT/13.9.2020.2437-2443

Table 5. Comparative results of user rights based on shopping mall

\begin{tabular}{|c|c|c|c|c|c|c|}
\multicolumn{1}{c|}{} & \multicolumn{2}{c|}{ KR } & \multicolumn{2}{c|}{ US } & \multicolumn{2}{c|}{ UK } \\
\hline Score & Gmarket & 11 st & Amazon & Ebay & ASOS & NEW LOOK \\
\hline 2 & 9 & 7 & 1 & 2 & 6 & 4 \\
\hline 1 & 0 & 2 & 0 & 0 & 0 & 0 \\
\hline 0 & 0 & 0 & 8 & 7 & 3 & 5 \\
\hline Total & 18 & 16 & 2 & 4 & 12 & 8 \\
\hline
\end{tabular}

Major U.S. shopping malls Amazon and Ebay, analyzed in this study, offer services in Korea, but servers are located overseas. Both companies are headquartered in the United States. For this reason, although it provides services in Korea, it is understood that it is writing basic things based on the laws of the country in which the head office is located and their servers are located. Therefore, based on the relevant laws of Korea, the evaluation result was significantly lower. The results show that major overseas shopping mall sites have created privacy policies based on the laws of the country where servers are mainly located, rather than those specified in Korean law.

The UK is currently following the EU's General Data Protection Regulations (GDPR). The GDPR provides for the main implementation rules of obtaining consent, notification of violations, access to personal information, right to be forgotten, mobility of information, privacy-centered design, information security officer, etc. Since most of the rights stated in the nation's related laws are included in the GDPR, the evaluation items based on the nation's related laws were also scored in compliance.
Among the above nine assessment items, the number of items clearly stated ( 2 point) averaged 5 , averaging $55.6 \%(=5 / 9)$ over the total. The number of items ( 0 point) not specified in the personal information processing policy of major shopping mall sites in the UK is $44.4 \%$ (=4/9), which is not disclosed more specifically than in Korea, but it can be seen that the contents are more specific than those of the U.S.

\subsection{Comparison of mobile carriers}

Results of Comparing and analyzing personal information processing policies on major telecommunication websites in Korea and abroad with comparison assessment items were that average score of Korean sites is 16.5 , that of U.S. sites is 7, and that of British sites is 9. In the case of major telecommunication websites in Korea, most of the contents of user rights that should be guaranteed by PERSONAL INFORMATION PROTECTION ACT of Korea are stated in the privacy policy.

Table 6. Mobile carrier base score

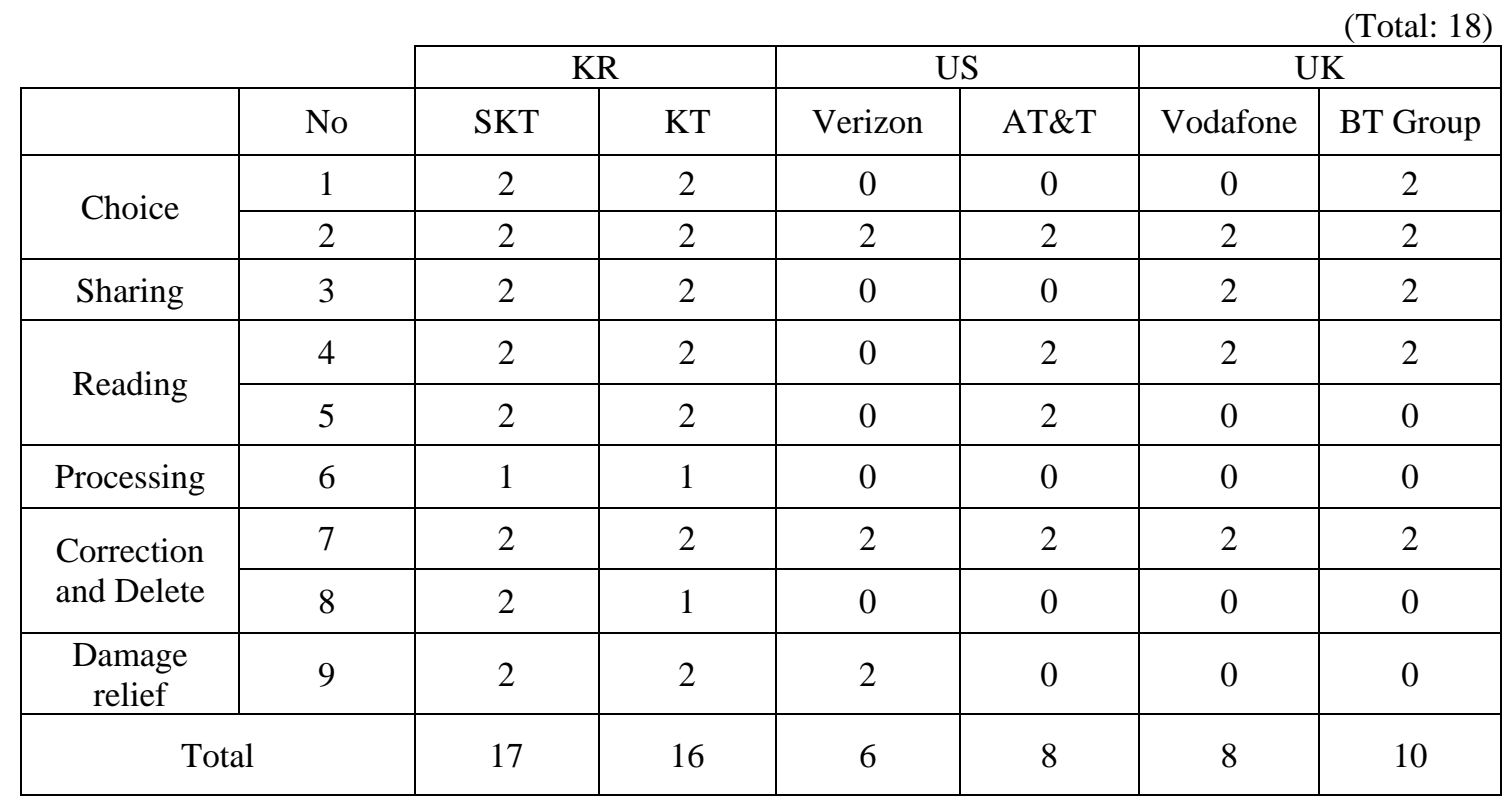

※ Detailed and clearly specified.: 2 points

※ It is specified, but it is not clear.: 1 point

※ot specified.: 0 point 
International Journal of Engineering Research and Technology. ISSN 0974-3154, Volume 13, Number 9 (2020), pp. 2437-2443

(C) International Research Publication House. https://dx.doi.org/10.37624/IJERT/13.9.2020.2437-2443

Table 7. Comparing results of user rights based on mobile carrier

\begin{tabular}{|c|c|c|c|c|c|c|}
\multicolumn{1}{c|}{} & \multicolumn{2}{c|}{ KR } & \multicolumn{2}{c|}{ US } & \multicolumn{2}{c|}{ UK } \\
\cline { 2 - 7 } Score & SKT & KT & Verizon & AT\&T & Vodafone & BT Group \\
\hline 2 & 8 & 7 & 3 & 4 & 4 & 5 \\
\hline 1 & 1 & 2 & 0 & 0 & 0 & 0 \\
\hline 0 & 0 & 0 & 6 & 5 & 5 & 4 \\
\hline Total & 17 & 16 & 6 & 8 & 8 & 10 \\
\hline
\end{tabular}

Verizon and AT\&T, major U.S. news agencies, received significantly lower scores based on Korea's related laws. Out of the above 9 evaluation items, the items that are clearly stated are an average of 3.5, which is an average of $38.9 \%(=3.5 / 9)$ compared to all items. In addition, the unspecified portion shows an average of $61.1 \%(=5.5 / 9)$, showing that more than half of the carriers differ from the related laws in Korea.

In the case of Vodafone and BT Group, major UK carriers, the average of the above 9 evaluation items is 4.5 , which is an average of $50 \%(=4.5 / 9)$ compared to the total. It is said that $50 \%(=4.5 / 9)$ of the UK's major shopping mall site is not specified in the Privacy Policy, which guarantees user rights similar to those of Korea.

\subsection{Comparison of portal sites}

Results of Comparing and analyzing personal information processing policies on major portal sites in Korea and abroad with comparison assessment items were that average score of Korean sites is 15.5 , that of U.S. sites is 10 , and that of British sites is 7. In the case of major portal sites in Korea, most of the contents of user rights that should be guaranteed by PERSONAL INFORMATION PROTECTION ACT of Korea are stated in the privacy policy.

Table 8 . Portal site base score

(Total: 18)

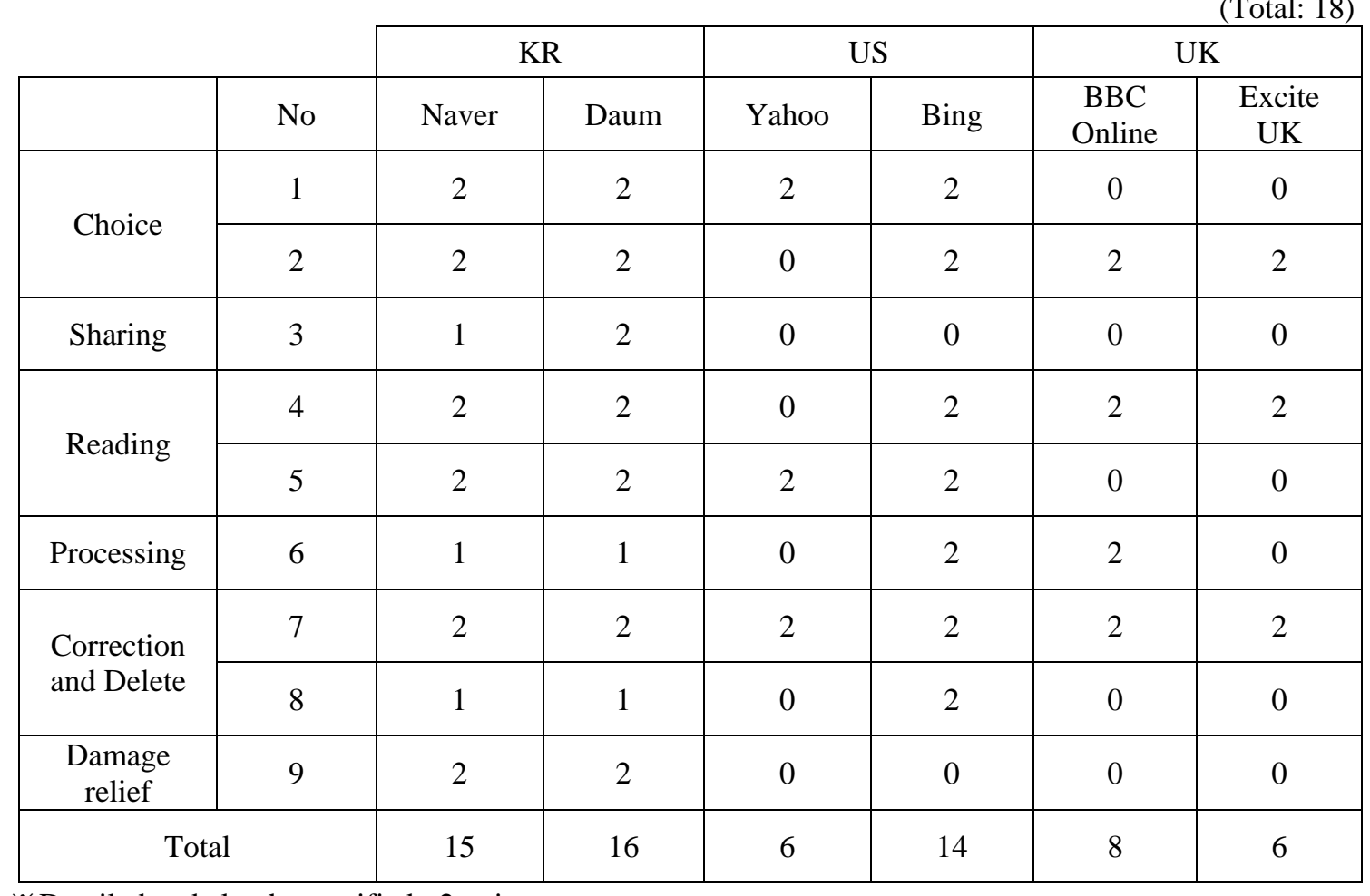

※ Detailed and clearly specified.: 2 points

※ It is specified, but it is not clear.: 1 point

※ Not specified.: 0 point 
International Journal of Engineering Research and Technology. ISSN 0974-3154, Volume 13, Number 9 (2020), pp. 2437-2443

(C) International Research Publication House. https://dx.doi.org/10.37624/IJERT/13.9.2020.2437-2443

Table 9. User rights comparison results based on portal site

\begin{tabular}{|c|c|c|c|c|c|c|}
\multicolumn{1}{c|}{} & \multicolumn{2}{c|}{ KR } & \multicolumn{2}{c|}{ US } & \multicolumn{2}{c|}{ UK } \\
\hline Score & Naver & Daum & Yahoo & Bing & BBC Online & Excite UK \\
\hline 2 & 6 & 7 & 3 & 7 & 4 & 3 \\
\hline 1 & 3 & 2 & 0 & 0 & 0 & 0 \\
\hline 0 & 0 & 0 & 6 & 2 & 5 & 6 \\
\hline Total & 15 & 16 & 6 & 14 & 8 & 6 \\
\hline
\end{tabular}

The major portal sites in the United States, Yahoo and Bing, are clearly specifying out of the above 9 evaluation items, with an average of 5 items, which is an average of $55.6 \%(=5 / 9)$ compared to all items. In addition, the part that is not clearly stated is $44.4 \%(=4 / 9)$ on average, which seems to be the most similar to the user rights guaranteed by Korean legal standards compared to other fields.

In the case of BBC Online and Excite UK, the major portal sites in the UK, among the nine items listed above, the average is clearly 3.5, which is an average of $38.9 \%(=3.5 / 9)$ compared to all items. The items analyzed as not specified in the major portal sites in the UK include the right to withdraw consent for collection, use, and provision of personal information, the right to receive information on processing, and access to the personal information of the child of the legal representative of a child under the age of 14 , the right to request, the right to request deletion and destruction, and the right to remedy damages caused by processing in accordance with prompt and fair procedures, and Excite UK does not specify the right to request suspension of processing.

\section{DISCUSSION AND IMPLICATION}

The first difference among major websites in Korea, the United States, and the United Kingdom is the scope of the privacy policy. The average score of shopping malls, telecommunications companies, and major portal sites is 16.3 in Korea, 6.7 in the United States, and 8.7 in the UK. The privacy policy major websites in Korea complies with the provisions of the PERSONAL INFORMATION PROTECTION ACT of Korea. In order to do so, it is written in a specific and narrow range, but the privacy policy of the United States and the United Kingdom is more comprehensive than that of Korea.

The second difference is that U.S. companies do not specifically provide access to data to data subjects. In the case of Korean company's websites, the average score is 8.5 out of 10 , based on 10 points, for items such as the right to check whether personal information is processed or not, the right to request the suspension of processing, the right to receive notice in correction, deletion, and limitation, and the right to access data of the children's legal representative under 14 years of age. However, U.S. company's websites scored 3.7 points on average.

Third, U.K. companies are actively dealing with user rights mentioned in the GDPR. It guarantees not only the rights guaranteed in Korea but also the right to demand the transfer of personal information so that personal information can be reused across various other services, but also the right to oppose the decision made by automated processing such as profiling. For example, UK shopping mall ASOS specifies the right to know how personal information is handled through 'Your Rights', access to personal information held, request for modification of personal information held, the right to withdraw consent to marketing messages and other consent-based processing at any time, the right to request users or other service providers to send or deliver elements of data, and the right to file complaints with their data protection regulators.

The privacy policies of major sites in Korea are not comprehensive, but rather very specific and the number of items is many to include compliance items specified by the law. On the contrary, the number of personal information processing policies of U.S. or U.K. portal sites was found to be less than those stipulated by Korean law. Therefore, there is also a strong tendency for the entity to assume that it has fulfilled its responsibilities if it only complies with the requirements set out in the privacy policy when a user's rights are violated.

This study analyzed national differences in user rights by comparing privacy policies, and suggests implications of research through this, but the calculation of scores is subjective and the distinction between scores is simple. To overcome these limitations, future studies need to reflect expert opinions and analyze them by dividing them into more feasible metrics. Further, further research will show differentiation from existing research by applying the automatic analysis method of unstructured data to carry out more systematic research.

\section{ACKNOWLEDGEMENTS}

This research was funded by a 2020 research Grant from Sangmyung University 


\section{REFERENCES}

[1] Lee Min-Yeong, Legal Issues on Privacy Policy Change of Google, "Internet and Information Security", $\operatorname{Vol}(3) 2, p p .18-33,2012$

[2] JANG WONCHANG, Ilsoon Shin, The Online Privacy Policy: Recognition, Confirmation and its Effects on Online Transaction Behavior, "Journal of the Korea Institute of Information Security \& Cryptology", vol.22, no.6, pp. 1419-1427, 2012

[3] Yun Ju Hee, A Study on the Application of Law According to Change of Privacy Policy - Focused on the Issues of Change the Privacy Policies of Facebook and Google,, "Law Journal”, no.41, pp. 391-428, 2013

[4] Noh Seung Hun, Kwon Tae Kyung, A Study on the Time Measurement for Reading the Privacy Policy, The Korea Society of Management information Systems, pp.896-899, 2014

[5] Jeon Chang Wook, Yoo Jin Ho, A Study on the Privacy Policy Comparison by Domestic and Foreign Portal Sites and Domestic Web Sites Classified by Industry, "Journal of the Korea Institute of Information Security \& Cryptology”, vol.26, no.3, pp.713-724, 2016

[6] Ham In Sun, The Enactment of 2016 General Data Protection Regulation(GDPR) in the EU and its Implications, "KOOKMIN LAW REVIEW", vol.36, 2016

[7] 6 major Web sites in Korea Gmarket, http://www.gmarket.co.kr/ 11 st, http://www.11st.co.kr/ SKT, http://www.tworld.co.kr/ KT, http://www.kt.com Naver, http://www.naver.com Daum, http://www.daum.net

[8] 12 major websites overseas Amazon, http://www.amazon.com eBay, http://www.ebay.com Verizon, http://www.verizon.com AT\&T, http://www.att.com Yahoo, http://www.yahoo.com Bing, http://www.bing.com ASOS, http://www.asos.com NEW LOOK, http://www.newlook.com/uk Vodafone, http://www.vodafone.co.uk BT Group, http://www.btplc.com BBC Online, http://www.bbc.com/ Excite UK, http://www.excite.co.uk 